\title{
Software tools for tasks of sustainable development of environmental problems: peculiarities of programming and implementation in the specialists' preparation
}

\author{
Andrii Iatsyshyn ${ }^{1,2,3,{ }^{*}, \text { Anna } \text { Iatsyshyn }^{2}, \text { Volodymyr Artemchuk }}{ }^{1,3}$, Iryna Kameneva $^{1}$, Valeriia Kovach $^{3,4}$, and \\ Oleksandr Popov ${ }^{1,3}$ \\ ${ }^{1}$ Pukhov Institute for Modelling in Energy Engineering of NAS of Ukraine, Kyiv, Ukraine \\ ${ }^{2}$ Institute of Information Technologies and Learning Tools of the NAES of Ukraine, Kyiv, Ukraine \\ ${ }^{3}$ State Institution "Institute of Environmental Geochemistry of NAS of Ukraine", Kyiv, Ukraine \\ ${ }^{4}$ National Aviation University, Kyiv, Ukraine
}

\begin{abstract}
It is necessary to follow signed documents on development of renewable energy, modernization of fuel and energy sector enterprises and waste management in order to fulfil Ukraine's commitments to the global community on climate change prevention. Therefore, it is an urgent task to develop software that allows to solve problems of visual analysis of environmental status dynamics of territorial systems and to determine boundaries of individual territories stability. The authors propose new forms of monitoring data presentation of technogenic loadings and risks which reflect dynamics of environmental situation in the space of informative features. It is important to improve skills of professionals, particularly, stuff of the ministries, enterprises and organizations responsible for decision-making to reduce negative impact on environment and to train future professionals in this area. Curriculums of higher education institutions do not pay much attention on usage of software to support managerial decision-making to reduce negative impact on the environment. It is proposed to improve qualification of such specialists, responsible for management in the following areas: conducting training seminars at the ministries, institutions and departments interested in the implementation of developed systems; scientific and methodological support and advisory assistance in the process of implementation of the software; development and improvement of educational and methodological support for postgraduate students and trainees of advanced training, specialists responsible for decision - making in energy, environmental and related fields.
\end{abstract}

\section{Introduction}

A report of the World Commission on Environment and Development "Our Common Future" defines sustainable development as "development that meets needs of modern times without sacrificing future generations to meet their own needs" [1]. From an environmental point of view sustainable development must ensure integrity and viability of natural systems, possibility of selfhealing and adaptation to change. In particular, the study of the relationship between environmental and economic components of sustainable development processes requires clarification of limit levels of technogenic loads and to determine the stability limits of urban territorial systems to technogenic impacts.

At this stage, approaches to sustainable development research can be divided into two directions. The first direction is dominant at the global and regional level (top view, i.e. comparative analysis of situation in different countries or regions). These studies aimed to calculate sustainable development indicators and indices according to the methods proposed by the UN Commission and international councils [2-5]. The next one should include work aimed to identify the stability of individual processes occurring in specific environmental or social systems [6-8]. Only real examples of dynamics analysis of individual systems can reveal dependence on trajectory development (or transition to critical state) of this system on values of the mentioned or other parameters.

Special attention should be given to the development and modernization of monitoring system of ecological status of territorial systems at different levels; to create universal information and monitoring software for monitoring tasks, improving tools of forecasting critical situations and to make necessary management decisions. It should be done for practical implementation of the principles of sustainable development in Ukraine. Development of modern information and computer technologies are focused on the storage, accumulation, systematization and integration of information obtained from various sources, including local level of data analysis and visual interpretation capabilities based on GIS technologies are among the top priorities that is evidenced by the accepted concept [9]. Its implementation should ensure compliance with

* Corresponding author: iatsyshyn.andriy@gmail.com 
international commitments in the field of environmental protection, rational use, renewal and protection of natural resources.

Therefore, we consider two aspects important for the research: improvement of monitoring system to forecast and managerial tasks to ensure environmental safety based on information technologies; professional development of specialists in the energy, environmental and related fields who are responsible for decisionmaking to reduce negative impact on environment.

\section{Analysis of previous publications}

Most publications on sustainable development have the following scholars: M. Zghurovs'kyj, P. Priyadarshini, H. Fredrickson, L. Zhao, S. González-García, J. Baleta, M.-H. Yuan, S.-L. Lo, A. Dawodu, A. Cheshmehzangi. Was made systematization of scientific publications in the following areas directly related to this research based on analysis of the works of foreign and domestic scientists:

- approaches to sustainable development [4, 6, 8, 10-13]; - development of indicators, indices to measure sustainable development [2, 14-21];

- construction of mathematical, software and hardware tools to assess impact of potentially dangerous enterprises on environment, taking into account economic indicators [22-33];

- training of specialists in the field of environmental safety and related industries [34-46].

However, further research should be dedicated to the questions of comprehensive and predictive assessments of environmental situation in technogenic territories in the context of sustainable development and skills development for professionals working in the energetic, environmental and related fields.

Aim: is to describe features of software application for sustainable development tasks and to outline directions of professional development of specialists responsible for management decisions in the energy, environmental and related fields.

\section{The research results}

\subsection{Energy industry: from environmental security to sustainable development}

One of the environmental safety assessing criteria of particular ecosystem is quality of life and health of population. There is need for purposeful impact (management) of ecological system in order to improve its organization and to achieve some beneficial effect.

Sustainable development models to measure system efficiency consist of economic, environmental and social subsystem were proposed in the research [10]. The result of the study is illustrated in 30 major Chinese cities. It shows main factors that affect their economic, environmental and social performance.

There is a need in planning and in policies that will be able to promote sustainable growth in order to conserve resources and guarantee social services and the well-being of citizens. Socio-economic analysis is essential for establishing a comprehensive diagnosis of the resilience of urban and rural systems in addition to environmental perspective. The work [11] presents methodology to assess sustainability based on 38 indicators that include three bases of sustainability: social, economic and environmental. This methodology was tested in many municipalities in north-western Spain. The research results showed that the most resilient municipalities are located in the north of the region. Size of municipalities is important to measure stability. The publication authors noted that developed methodology is reliable and can be applied to other municipalities and cities.

Joint efforts and a multidisciplinary approach are needed to address global warming. Circular economics together with resource efficiency is focus of researchers and politicians. Sustainable development is a multidisciplinary topic. Interaction of energy, water and environment plays central role. In circular economy paradigm there is growing need for system integration when by-product of one system can represent resource for another. The research [12] highlighted issues of sustainable development of energy, water and environment systems. It was emphasized that more efforts should be made to further integration of these systems. All listed above leads to increase in complexity of such problem. It can be only solved by collaboration of many scientists from different fields of research.

Integration of energy, water and environment systems is important in the multidisciplinary concept of sustainable development as they represent basic necessities of humanity. Therefore, problems arising from the concept of sustainable development should be carefully addressed to conserve energy, water and environmental resources for future generations. Some recent developments in these major areas of sustainable development are discussed in [13].

\subsection{Problem statement for sustainable monitoring for territories development}

Environmental monitoring includes system of observations on factors that affect environment, process for assessing of the environment actual state, estimation, certain control and management capabilities. Environmental indicators are considered as separate indicators with significant impact on status of studied areas. Environmental indexes are considered as complex indicators.

Structural approach to assess the state of individual territories is developed for problems of impact analysis and technogenic impact. It is substantiated to determine indicators of environmental status (integral indices) based on data of urbanized territories monitoring in work [20]. Three types of environmental indicators are proposed to identify indicators of the urban areas environmental status:

1) the most informative among indicators recorded as result of measurements at the posts (concentrations of 
the most dangerous substances);

2) multidimensional indices of ecological status of studied territories, based on set of measured indicators;

3) environmental risk estimation (probability distributions or risk fields) calculated on the basis of monitoring data.

Generalized estimations (indicators) of ecological status of these territories are determined on the basis of ecological monitoring data of the studied territories under conditions of high technogenic loads.

Site planning, construction and deployment of industrial facilities, land and natural resource management, vehicle management, agricultural development, accident or emergency simulation are typical sustainable development tasks that require the use of spatial analysis tools and technologies [2].

There are following tasks of monitoring, analyzing and evaluation of sustainable development of regions and individual territories: identification of spatial structure of systems under study (distribution of technogenic loads, distribution of risks and diseases, identification of dangerous zones); analysis of certain changes and determination of main trends for studied period (monitoring of dynamics of technogenic loads); predicting of possible scenarios for typical situations (in particular, assessing of potential impact of dangerous factors and effectiveness of management decisions).

One of priority tasks for assessment and modeling of sustainable development processes at territorial level is to determine stability limits of studied territorial systems under pressure of high technogenic loads.

Natural boundaries of sustainability in the concept of sustainable development determine state of biosphere and society which will preserve our civilization and basic natural resources for future generations. Therefore, it is necessary to determine such maximum permissible levels of load on separate territorial systems for which stable state can still be ensured [47].

Let's remember the definition of stability by Lyapunov in order to clarify the concept of the stability of dynamic systems. Trajectory of dynamic system can be considered stable if for any number of small deviations (that determine limits of stability of this system) such constraints can be specified for possible vibrations at which the system does not go beyond certain limits [48].

There are main stages of territorial systems research in order to determine stability limits to impact of technogenic loads.

1. Spatial analysis of man-made pollution monitoring data and identification of high-risk areas. In preliminary stages of analyzing monitoring data it is necessary to determine informative parameters (or environmental indexes) that are used to rank the sites and build environmental scales.

2. Results visualization of spatial analysis in the form of two-dimensional semantic scales, i.e. informative projections of semantic space of risks. It provides assessment and ranking of the studied territories by the indices of ecological status.

3. Visual analysis of technogenic loads dynamics over period of time in high-risk zones (maximum voltage points) using stability scales and visual determination of the stability limits.

\subsection{Analysis of tools and results}

The authors of this publication developed an analytical and information system to monitor the technogenic environmental loads in order to study the spatialdistributed tasks of anthropogenic impact analysis on territorial systems. This monitoring system provides possibility to analyse complex processes and phenomena that reflect monitoring data of individual cities, regions or territorial systems. This software consists of several blocks, namely: block of statistical analysis and preliminary estimation of technogenic atmospheric loads; mathematical modeling and forecasting unit of atmospheric pollution and risks for the population; block of visualization and construction of ecological maps [26].

This system can be used as auxiliary tool for informational support of environmental monitoring tasks, monitoring of pollution from potentially dangerous objects, ecological safety management in conditions of technogenic pollution of atmosphere surface layer. It is necessary to support decision-making on ensuring civil protection of population and territories with increased technogenic loads. Developed software can provide local governments and other stakeholders with valuable information that is necessary to make the most effective decisions based on local outcomes.

Fig. 1 shows block diagram of software to manage environmental safety of urban areas. It includes tool to model and forecast technogenic environmental loads (in particular, atmospheric air) from stationary sources of pollution.

Methodological analysis of sustainable development processes requires determination of stability criteria of studied territorial systems. It needs to be known in order to calculate the restrictions on technogenic loads.

Task of defining such criteria can be seen as inverted to task of monitoring of technogenic loads at local level, i.e. task of those boundaries clarifying which can lead to catastrophic changes in systems under study.

Special attention should be paid to the development of tools for visual analysis of monitoring data and technologies for the construction of ecological scales among methodological tools aimed at determining the boundaries of urban areas sustainability. It provides visual reflection of changes dynamics in ecological status of territorial system over researched period.

Let's consider some of the graphical visualizations of processes under research based on computer-based visual observation of approaching boundary conditions process. It is necessary to take into account monitoring data and regulatory data on restrictions on maximum permissible concentrations and risks.

The proposed tool to change dynamics in ecological status analyzing and to determine the stability of urban areas boundaries to technogenic impact were tested on the example of the territorial system of Kyiv, Ukraine. The research was conducted using the city's atmospheric 
air monitoring data from the Sreznevsky Central Geophysical Observatory from 2005 to 2018 [49].

In the previous stages of analysis, the most informative indicators of pollution were identified to monitor the dynamics of technogenic loads on the city. They have high danger class, large range of seasonal fluctuations and significantly exceed limits established by the current legislation. Dynamics peculiarities of technogenic influence on the surface layer of air were investigated on the examples of such dangerous substances - pollutants such as formaldehyde, nitrogen dioxide and carbon monoxide.

Values of risks for the population of different districts of Kyiv were determined based on the monitoring data. Chronic intoxication risk ( $\mathrm{RCI})$ and risk of immediate toxic effects (RITE) were calculated using the formulas described in [50]. Dynamics of health risks can be monitored at specific points in the city according to these data. Estimates of risks for population for the study period are given in Table 1. Fig. 2 shows examples of risk maps due to air pollution in Kyiv, JanuaryDecember 2017.

According to the given above data the highest values of technogenic loads and risks during the researched period were observed for Besarabska Square. It was marked as an area of high risk (observation point No 7). Also increased risk values in the observation period were noted at pollution observation stations (POS) of other central areas of the city (Nezalezhnosti Square, Peremohy Square, etc.).

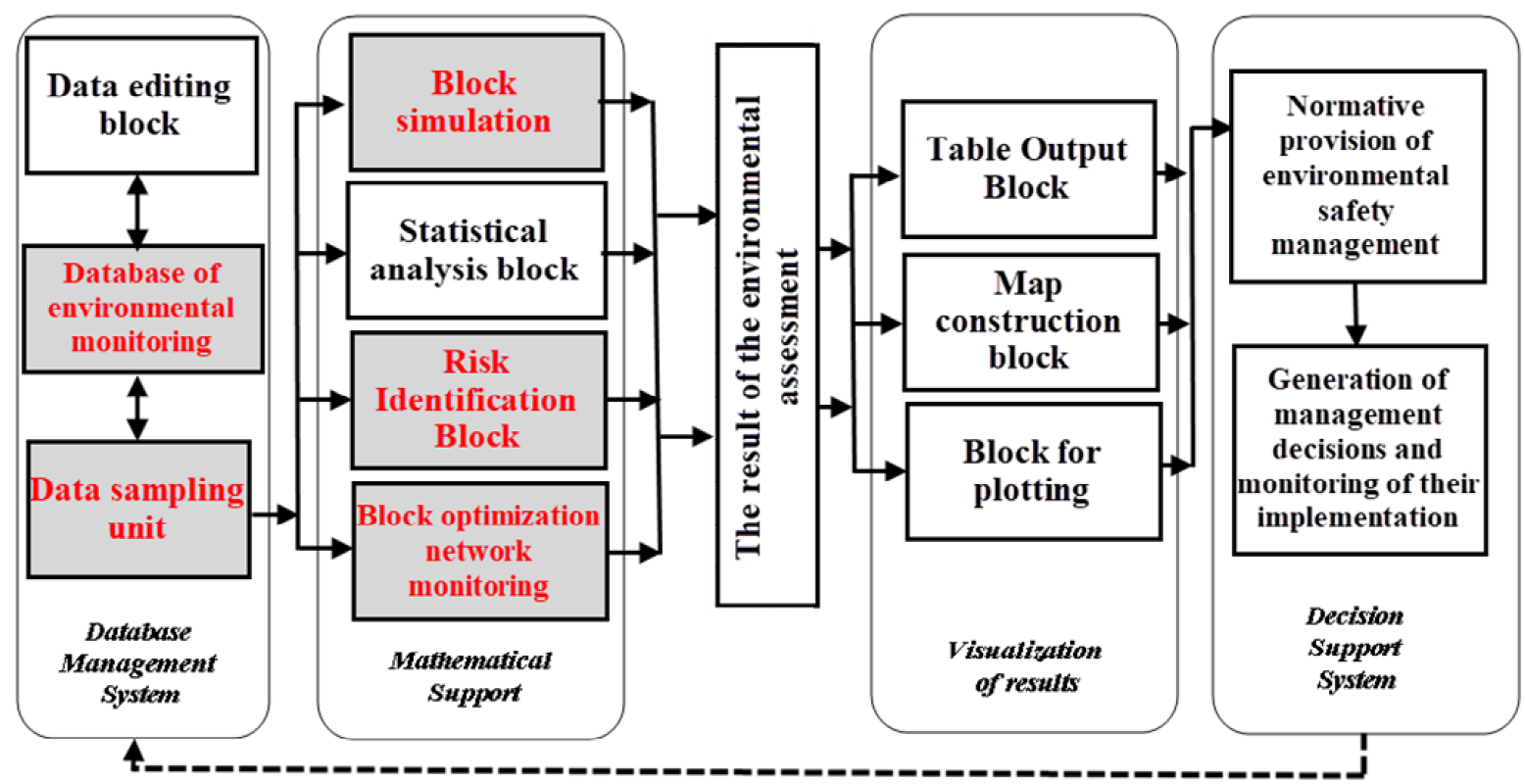

Fig. 1. Created software to provide safety.

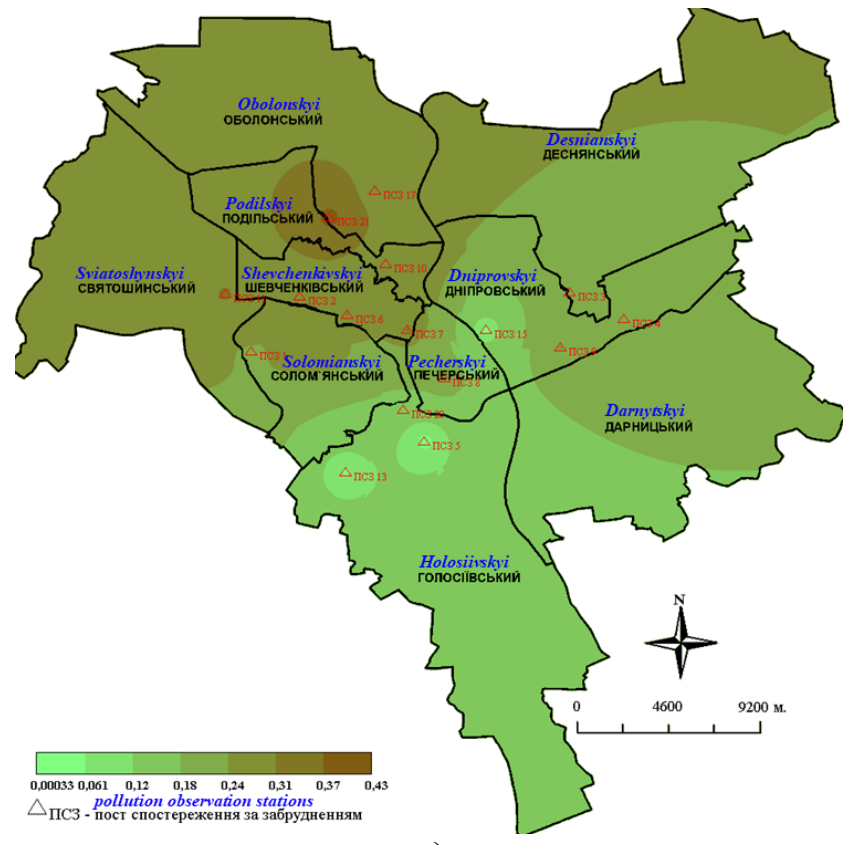

a)

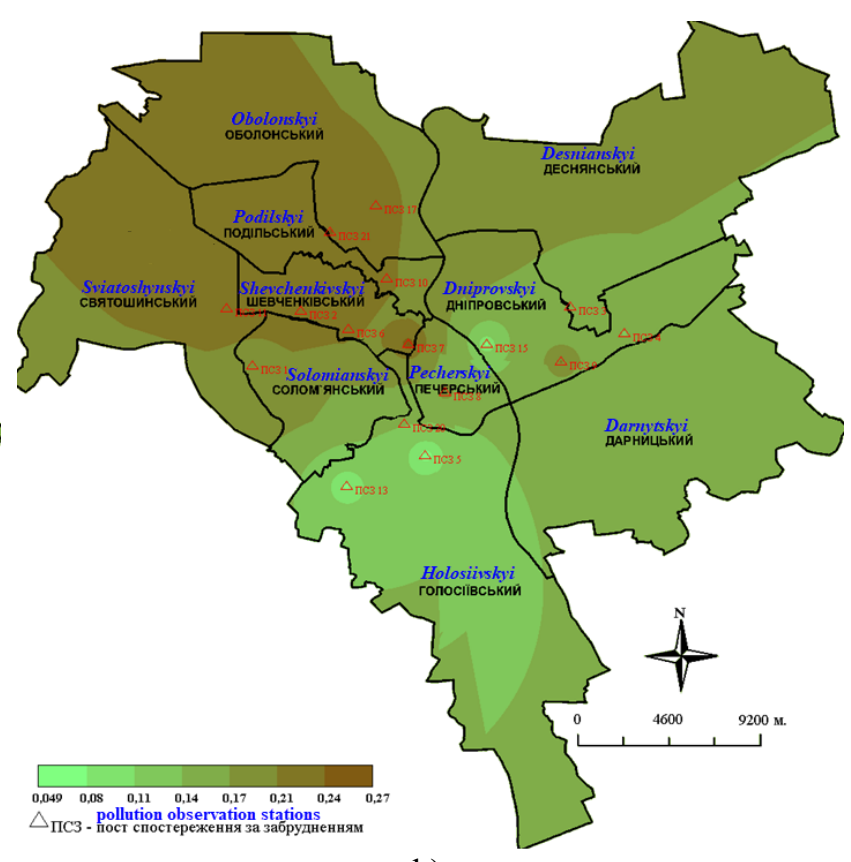

b)

Fig. 2. RITE (a) and RCI (b) as a result of air pollution in Kyiv in January-December 2017 [26]. 
Table 1. Dynamics of risk values for the health of the population in Kyiv.

\begin{tabular}{|l|c|c|c|c|c|c|}
\hline \multirow{2}{*}{\multicolumn{1}{c|}{ Location }} & \multicolumn{2}{|c|}{2008} & \multicolumn{2}{c|}{$\mathbf{2 0 1 1}$} & \multicolumn{2}{c|}{$\mathbf{2 0 1 7}$} \\
\cline { 2 - 7 } & RITE & RCI & RITE & RCI & RITE & RCI \\
\hline Peremohy Square & 0.298 & 0.136 & 0.306 & 0.210 & 0.226 & 0.219 \\
\hline Demiivska Square & 0.089 & 0.060 & 0.157 & 0.144 & 0.160 & 0.178 \\
\hline $\begin{array}{l}\text { National complex } \\
\text { "Ekspocentr Ukraina" }\end{array}$ & 0.120 & 0.053 & 0.032 & 0.071 & 0.067 & 0.087 \\
\hline Darnytska Square & 0.358 & 0.151 & 0.215 & 0.174 & 0.187 & 0.182 \\
\hline Maidan Nezalezhnosty & 0.390 & 0.202 & 0.264 & 0.212 & 0.202 & 0.241 \\
\hline Bessarabska Square & 0.472 & 0.275 & 0.321 & 0.255 & 0.211 & 0.296 \\
\hline Hydropark & 0.140 & 0.063 & 0.025 & 0.068 & 0.026 & 0.077 \\
\hline
\end{tabular}

Specialized visual tools of displaying monitoring data on exceeding the maximum permissible concentration levels and corresponding risk values were developed to monitor seasonal dynamics of technogenic loads on individual territories and to identify the most dangerous situations. It is possible to formulate certain sequence of graphic images and to determine the most dangerous deviations from the stable state comparing the results obtained by the authors.

On the first stage it is necessary to outline image of normal state located closer to the origin where exceeding the limit values does not reach critical values. Then it is necessary to distinguish maximum deviations from the norm directed in the opposite direction.

Fig. 3 shows dynamics of atmospheric pollution index for the period from 2015 to 2018 at POS No 7 (district of Besarabska Square). Obtained graph can be considered as the most meaningful reflection of observations results. It takes into account data on main air pollutants in recent years.

Normal values are concentrated closer to coordinate axes five times lower than maximum values. The most dangerous situations form external contour. It starts from point above (6.2016) and is limited by maximum risks shown on the right part of chart.

Separate observations (monthly average pollution data) are indicated by rectangles showing month and year of observation. On the graph the monthly average values are interconnected in order in which the measurements took place.

It is possible to visually identify the most dangerous situations (or periods of maximum deviation from the norm) when local disturbances of stable condition are characterized by significant increase in population morbidity on the adjacent territories. It can be done by the proposed software for monitoring technogenic loads in certain territories.

Indices of ecological status of urban areas were calculated on the basis of monitoring data of Kyiv for analysis of sustainable development processes at local and regional levels, according to the recommendations given in [3]. At the present time the developed software modules were implemented at the Department of organization of civil protection measures of the SES of Ukraine, at separate unit of the Scientific and Technical Center of the state enterprise "NAEK Energoatom" (SE "NAEK Energoatom"). Recommendations on application of the developed software at territorial and interregional units of the State ecological inspection of Ukraine were obtained.

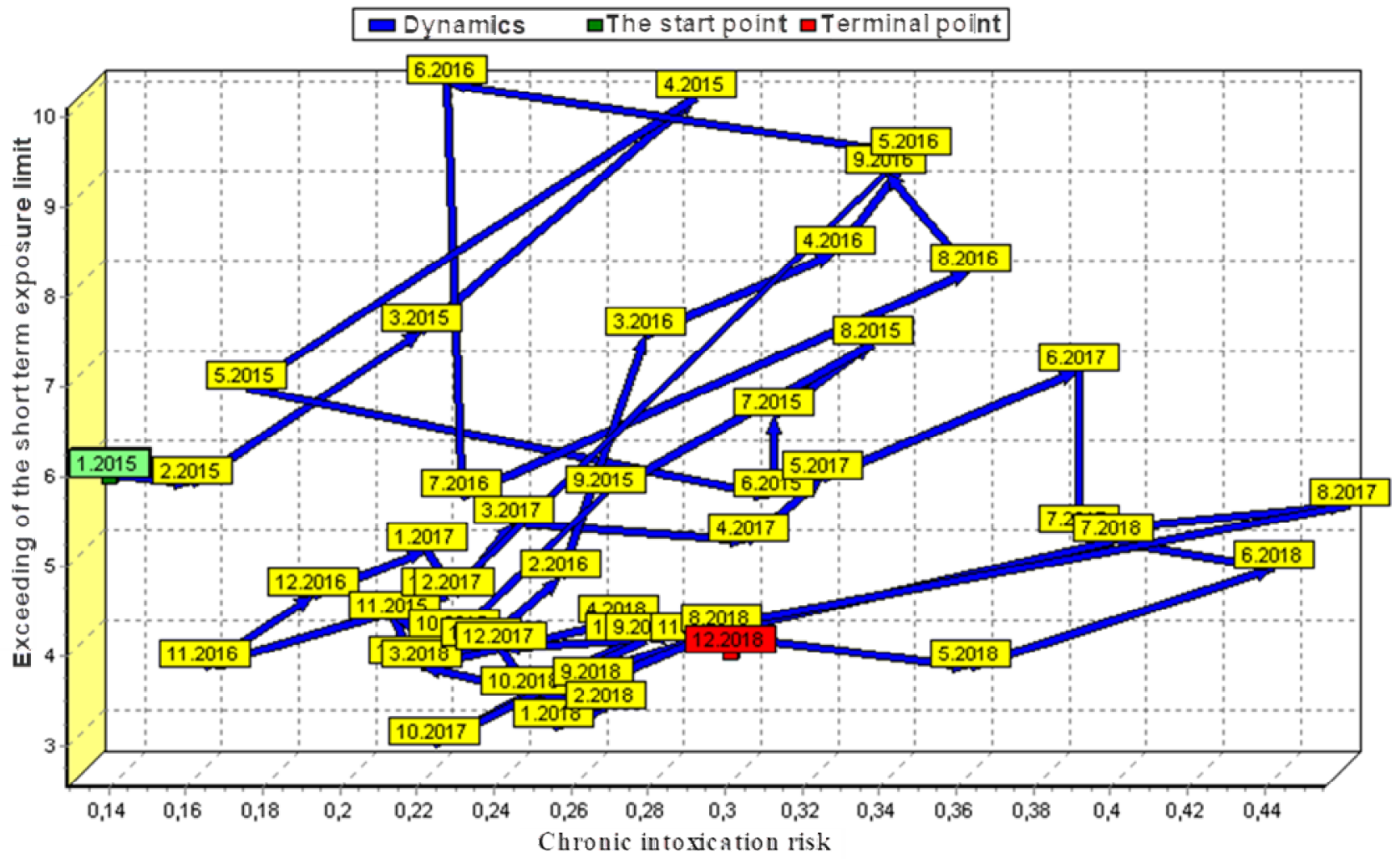

Fig. 3. Dynamic of the atmosphere pollution index at POS No 7 (2015-2018). 
The developed software can provide population with information about the environment state, existing environmental risks/threats to safe living presented electronically. It is especially important when creating nationwide automated information and analytical system "Open Environment".

There are estimations obtained from the analysis of real monitoring data and modeling of anthropogenic loads on particular areas. They should be correlated with those boundary conditions that meet the criteria of sustainability approved by international and national legislation to determine the boundaries of sustainability of urban areas.

\subsection{Application areas of the software tools for advanced training of specialists in the energy sector, environmental and related fields}

Application proposals of higher education institutions of Ukraine (National University of Bioresources and Environmental Management of Ukraine, Odessa State Ecological University, State Ecological Academy of Postgraduate Education and Management, etc.) for 2019 were analyzed. Analysis determined that these institutions offer training under the programs of additional professional education - and long-term skills development courses in full-time and part-time forms. The advanced training programs were developed in the field of Earth sciences (meteorology, agrometeorology, hydrology), ecology and others. Courses of advanced training in different directions and topics are offered: assessment of the state and technogenic impact of the motor transport complex on the environment, protection of the atmospheric air, design and operation of modern environmental monitoring systems, training of public environmental inspectors, basics of geoinformation systems and technologies course for users) and others. The offered skills development courses are aimed to improve professional activity of specialists to work in positions of managers and leading executives in management, ecology and nature management. Scientific enterprise "Infotech" developed an innovative virtual environment (consisting of a full-function web-based simulator and a distance training course) for training and skills development of staff of integrated energy system of Ukraine during the distance forms of training in order to improve the qualification of the personnel in the energy sector of Ukraine.

We believe that it is important to implement software tools to support managerial decision-making in the professional development of specialists in the energy, environmental and related fields. It corresponds to the modern world requirements for the training of specialists of new technological era. It will contribute to realization of the sustainable development concept of society. Experts using such software will be able to: identify previously unknown relationships between environmental parameters and environmental factors; identify and predict latent trends and patterns of development of environmental processes (identify hidden factors of influence, including threat factors; systematize and integrate environmental data; develop optimization recommendations in energy, environmental and related industries; prepare preliminary reports and draft feasible decisions, etc.).

In 2019 the authors developed algorithms, mathematical and software tools to test environmental effectiveness of management decision-making. It is an important component in assessing of sustainable development of environmental systems. Also, the authors of this article provide advisory assistance and scientific support to organizations and institutions in order to improve skills of professionals in the energy, environmental and related fields (in particular in application of management decision support software).

\section{Conclusions}

The software was developed to solve problems of visual analysis of ecological status dynamics of territorial systems and to determine boundaries of sustainability of individual territories. New forms of presentation of monitoring data of anthropogenic loads and risks are presented to analyze the dynamics of anthropogenic impact and to determine the boundaries of stability of local systems. It reflects ecological situation dynamics in the space of informative features.

It is also important to improve skills of professionals particularly in ministries, business and organizational staff responsible for decision-making to reduce negative impact on environment and to train future professionals in this area. Only a few higher education institutions offer training courses for stuff who are working in the sphere of management, ecology and nature use. But it is not paid much attention on training to use managerial decision support software. The main areas of professional development of the specialists responsible for management are: conducting training seminars at the ministries, institutions and departments interested in implementing the developed systems; scientific and methodological support and advisory assistance in the process of implementation of the developed software; development and improvement of educational and methodological support for postgraduate students and trainees of advanced training of specialists responsible for management decisions in energy, environmental and related fields.

\section{References}

1. G.H. Brundtland, M. Khalid, S. Agnelli, S. AlAthel, B. Chidzero, Our common future (New York, 1987)

2. M.Z. Zghurovs'kyj, Analysis of Sustainable Development: Global and Regional Contexts (NTUU “KPI”, Kyiv, 2012)

3. Report On Aggregation Indicators for Sustainable Development (UN Division on Sustainable Development, New York, 2001)

4. P. Priyadarshini, P.C. Abhilash, From Piecemeal to Holistic: Introducing Sustainability Science in 
Indian Universities to Attain UN-Sustainable Development Goals. J. Clean. Prod. 119133 (2019)

5. X. Wang, H. Ren, P. Wang, R. Yang, L. Luo, F. Cheng, A Preliminary Study on Target 11.4 for UN Sustainable Development Goals. International Journal of Geoheritage and Parks 6(2), 18-24 (2018)

6. E. Yıldız-Geyhan, G. Yılan, G.A. Altun-Çiftçioğlu, M.A.N. Kadırgan, Environmental and social life cycle sustainability assessment of different packaging waste collection systems. Resources, Conservation and Recycling 143, 119-132 (2019)

7. H.L. Fredrickson, Towards Understanding and Managing Sustainable Complex, Dynamic Environmental/Economic/Social Systems-The Evolving Role of the Natural Sciences, in Encyclopedia of Sustainable Technologies (2017), pp. 3-9

8. T. Niemmanee, R. Kaveeta, C. Potchanasin, Assessing the Economic, Social, and Environmental Condition for the Sustainable Agricultural System Planning in Ban Phaeo District, Samut Sakhonn Province, Thailand. Procedia - Social and Behavioral Sciences 197, 2554-2560 (2015)

9. About the approval of the Concept of creation of the national automated system "Open environment", Order of the Cabinet of Ministers of Ukraine. Conception on 7.11.2018 No 825, https://zakon.rada.gov.ua/laws/show/825-2018$\% \mathrm{D} 1 \% 80$. Accessed 30 Mar 2020

10. L. Zhao, Y. Zha, Y. Zhuang, L. Liang, Data envelopment analysis for sustainability evaluation in China: Tackling the economic, environmental, and social dimensions. European Journal of Operational Research 275(3), 1083-1095 (2019)

11. S. González-García, M. Rama, A. Cortés, et al, Embedding environmental, economic and social indicators in the evaluation of the sustainability of the municipalities of Galicia (northwest of Spain). J. Clean. Prod. 234, 27-42 (2019)

12. J. Baleta, H. Mikulčić, J.J. Klemeš, K. Urbaniec, N. Duić, Integration of energy, water and environmental systems for a sustainable development. J. Clean. Prod. (2019)

13. H. Mikulčić, X. Wang, N. Duić, R. Dewil, Environmental problems arising from the sustainable development of energy, water and environment system. J. Environ. Manag. (2019)

14. J. Reid, M. Rout, Developing sustainability indicators - The need for radical transparency. Ecol. Indic. 110 (2020)

15. J.H.P.P. Eustachio, A.C.F. Caldana, L.B. Liboni, D.P. Martinelli, Systemic indicator of sustainable development: Proposal and application of a framework. J. Clean. Prod. 241 (2019)

16. T. Chowdhury, H. Chowdhury, P. Chowdhury, S.M. Sait, A. Paul, J. Uddin Ahamed, R. Saidur, A case study to application of exergy-based indicators to address the sustainability of Bangladesh residential sector. Sustain. Energy Techn. 37 (2020)

17. M.-H. Yuan, S.-L. Lo, Developing indicators for the monitoring of the sustainability of food, energy, and water. Renew. Sust. Energ. Rev. 109565 (2019)

18. A. Dawodu, A. Cheshmehzangi, B. Akinwolemiwa, The systematic selection of headline sustainable indicators for the development of future neighbourhood sustainability assessment tools for Africa. Sustain. Cities Soc. 41, 760-776 (2018)

19. M. Köhl, H.-P. Ehrhart, M. Knauf, P.R. Neupane, A viable indicator approach for assessing sustainable forest management in terms of carbon emissions and removals. Ecol. Indic. 111, 106057 (2020)

20. Report Software development for analyzing and forecasting of anthropogenic risks at local and regional levels in the problems of planning and management of sustainable development (PIMEE NASU, Kyiv, 2014)

21. S. Bondarenko, B. Liliya, K. Oksana, G. Inna, Modelling instruments in risk management. International Journal of Civil Engineering and Technology 10(1), 1561-1568 (2019)

22. A. Zaporozhets, V. Eremenko, R. Serhiienko, S. Ivanov, Methods and Hardware for Diagnosing Thermal Power Equipment Based on Smart Grid Technology, in Advances in Intelligent Systems and Computing III, CSIT 2018. Advances in Intelligent Systems and Computing, vol. 871, (2019) pp. 476489

23. A.O. Zaporozhets, V.S. Eremenko, R.V. Serhiienko, S.A. Ivanov, Development of an intelligent system for diagnosing the technical condition of the heat power equipment, in XIII International Scientific and Technical Conference "Computer Sciences and Information Technologies" (CSIT 2018), pp. 48-51

24. A. Zaporozhets, S. Kovtun, O. Dekusha, System for Monitoring the Technical State of Heating Networks Based on UAVs, in Advances in Intelligent Systems and Computing IV, CCSIT 2019. Advances in Intelligent Systems and Computing, vol. 1080 (2020)

25. V. Bogorad, Y. Bielov, Y. Kyrylenko, T. Lytvynska, V. Poludnenko, O. Slepchenko, Forecast of the consequences of a fire in the Chernobyl Exclusion Zone: A combination of the hardware of the mobile laboratory RanidSONNI and computer technologies DSS RODOS. Nuclear and Radiation Safety 3(79), 10-15 (2018)

26. O.O. Popov, A.V. Iatsyshyn, V.O. Kovach, V.O. Artemchuk, I.P. Kameneva, D.V. Taraduda, V.O. Sobyna, D.L. Sokolov, M.O. Dement, T.M. Yatsyshyn, Risk Assessment for the Population of Kyiv, Ukraine as a Result of Atmospheric Air Pollution. Journal of Health and Pollution 10(25), 200303 (2020)

27. O. Popov, A. Iatsyshyn, V. Kovach, V. Artemchuk, D. Taraduda, V. Sobyna, D. Sokolov, M. Dement, V. Hurkovskyi, K. Nikolaiev, T. Yatsyshyn, D. 
Dimitriieva, Physical Features of Pollutants Spread in the Air During the Emergency at NPPs. Nuclear and Radiation Safety 4(84), 88-98 (2019)

28. O.A. Ivashhuk, D.A. Kvanin, Automated environment safety management of the local urban territories. Information Systems and Technologies 4(84), 62-68 (2014)

29. C. Suo, Y.P. Li, J. Sun, S. Yin, An air quality indexbased multistage type-2-fuzzy interval-stochastic programming model for energy and environmental systems management under multiple uncertainties. Environ. Res. 167, 98-114 (2018)

30. M. Rönkkö, J. Heikkinen, V. Kotovirta, V. Chandrasekar, Automated preprocessing of environmental data. Future Gener. Comp. Sy. 45, 13-24 (2015)

31. I.V. Blinov, Ye.V. Parus, H.A. Ivanov, Imitation modeling of the balancing electricity market functioning taking into account system constraints on the parameters of the IPS of Ukraine mode. Technical Electrodynamics 6, 72-79 (2017)

32. T. Yatsyshyn, Y. Mykhailiuk, M. Liakh, I. Mykhailiuk, V. Savyk, I. Dobrovolsky, Establishing the dependence of pollutant concentration on operational conditions at facilities of an oil and gas complex. Eastern-European Journal of Enterprise Technologies, 2(10-92), 56-63 (2018)

33. O. Popov, A. Iatsyshyn, V. Kovach, V. Artemchuk, D. Taraduda, V. Sobyna, D. Sokolov, M. Dement, T. Yatsyshyn, Conceptual Approaches for Development of Informational and Analytical Expert System for Assessing the NPP impact on the Environment. Nuclear and Radiation Safety 3(79), 56-65 (2018)

34. L.Y. Shkitsa, V.G. Panchuk, V.A. Kornuta, Innovative methods of popularizing technical education, in Proceedings of the Conference Innovative Ideas in Science 2016. IOP Conference Series: Materials Science and Engineering 200, 012023 (2016)

35. L.Y. Shkitsa, V.A. Kornuta, O.V. Kornuta, I.O. Bekish, The model of informational space for innovation and design activities in the university, Science and Innovation 15(6), 14-22 (2019)

36. V. Gurieiev, O. Sanginova, Simulation and study of modes for full-scale mode simulator for Ukrainian energy systems, in Proceedings of the 2nd International Conference on Intelligent Energy and Power Systems (IEPS'2016) (2016)

37. V. Gurieiev, O. Sanginova, Distributed simulation environment of modes for full-scale mode simulator for Ukrainian energy systems. Technical Electrodynamics 5, 67-69 (2016)

38. Anna V. Iatsyshyn, V.O. Kovach, Ye.O. Romanenko, I.I. Deinega, Andrii V. Iatsyshyn, O.O. Popov, Yu.G. Kutsan, V.O. Artemchuk, O.Yu. Burov, S.H. Lytvynova, Application of augmented reality technologies for preparation of specialists of new technological era. CEUR Workshop Proceedings 2547, 181-200 (2019)

39. Anna V. Iatsyshyn, V.O. Kovach, V.O. Lyubchak, Y.O. Zuban, A.G. Piven, O.M. Sokolyuk, Andrii V. Iatsyshyn, O.O. Popov, et al., Application of augmented reality technologies for education projects preparation. CEUR Workshop Proceedings (2020 in press)

40. A. Vergara, M.P. Rubio, M. Lorenzo, On the Design of Virtual Reality Learning Environments in Engineering, Multimodal Technologies and Interactions 1, 11 (2017)

41. S.I. Pochtoviuk, T.A. Vakaliuk, A.V. Pikilnyak, Possibilities of application of augmented reality in different branches of education. CEUR Workshop Proceedings 2547, 92-106 (2019)

42. Y.O. Romanenko, I.V. Chaplay, Marketing communication system within public administration mechanisms. Actual Problems of Economics, 178(4), 69-78 (2016)

43. I.S. Bakhov, Dialogue of Cultures in Multicultural Education. World Applied Sciences Journal 29(1), 106-109 (2014)

44. T.A. Vakaliuk, V.V. Kontsedailo, D.S. Antoniuk, O.V Korotun, I.S. Mintii, A.V. Pikilnyak, Using game simulator Software Inc in the Software Engineering education. CEUR Workshop Proceedings 2547, 66-80 (2019)

45. T.A. Vakaliuk, O.V. Korotun, D.S. Antoniuk, Selection of the Cloud-Oriented Database Learning Tools for Future IT Professionals. Information Technologies and Learning Tools 71(3), 154-168 (2019)

46. J. Grodotzki, T.R. Ortelt, A.E. Tekkaya, Remote and Virtual Labs for Engineering Education 4.0. Procedia Manuf. 26, 1349-1360 (2018)

47. United Nations Conference on the Human Environment, Rio Declaration on Environment and Development (Rio de Janeiro, Brazil, United Nations, 1992)

48. B.P. Demidovich, Lectures on the Mathematical Stability Theory (Nauka, Moscow, 1967)

49. Monthly Bulletin of air pollution in the cities of Kyiv and Kyiv region, Central Geophysical Observatory named after Boris Sreznevsky, Kiev, Ukraine (20052018)

50. V.T. Alyimov, N.P. Tarasova, Technogenic risk: Analysis and evaluation: A manual for higher education institutions (Akademkniga, Moscow, 2004) 